\title{
Surgical resection of cardiac myxoma-a 30-year single institutional experience
}

\author{
Kyo Seon Lee, Gwan Sic Kim, Yochun Jung, In Seok Jeong, Kook Joo Na, Bong Suk Oh, Byung Hee Ahn \\ and Sang Gi Oh*
}

\begin{abstract}
Background: Primary cardiac tumors are rare and myxoma constitutes the majority. The present study summarizes our 30-year clinical outcomes of surgical myxoma resection.

Methods: Between January 1986 and December 2015, 93 patients (30 men, 63 women; mean age, $54.7 \pm 16.6$ years) underwent surgical myxoma resection. The most common origin site was the left atrium. Surgery was performed via a biatrial approach in $74.2 \%$, atrial septotomy through right atriotomy in $17.2 \%$, and left atriotomy only in $8.6 \%$. Mean myxoma size based on longest length was $4.73 \pm 1.92 \mathrm{~cm}$ (range, 1.2-11.0 cm).

Results: The mean follow-up duration was $9.9 \pm 7.8$ years (range, $0-29$ years). In-hospital mortality was 3.2\%. The most common postoperative complication was atrial fibrillation (4.3\%). The 5-, 10-, and 30-year survival rates were 92.9\%, 87. $2 \%$, and $75.5 \%$, respectively. Recurrence occurred in two patients (2.1\%), which were detected at 20 and 79 months after the first surgery, respectively.
\end{abstract}

Conclusions: Long-term survival after myxoma resection was excellent and recurrence was rare. Based on our experience, surgical method did not affect the outcome.

Keywords: Myxoma, Benign cardiac tumor

\section{Background}

Primary cardiac tumors are rare and approximately $70 \%$ are benign. Myxoma is the only relatively common primary heart neoplasm [1,2], which is often found on 2-dimensional (2D) echocardiography. Myxoma occurs in all ages and is 2 to 3 times more common in women than in men. It can cause mild constitutional symptoms, such as fever, weight loss, myalgia, or arthralgia, to serious hemodynamic derangement, depending on its location and size, which can lead to disastrous embolic symptoms. Therefore, if possible, prompt surgical resection is recommended.

The objective of this study was to assess our longterm clinical outcomes of intracardiac myxoma resection in a consecutive series of 93 patients.

\footnotetext{
* Correspondence: waytogosun@gmail.com

Department of Thoracic and Cardiovascular Surgery, Chonnam National University Hospital, Chonnam National University School of Medicine, 42, Jebong-ro, Dong-gu, Gwangju 15772, South Korea
}

\section{Methods}

From January 1986 to December 2015, 93 patients with cardiac myxoma underwent surgery at our institution. Myxoma was 2 times more common in women (63 patients, $67.7 \%$ ) than in men (30 patients, $32.3 \%$ ), and the mean age of the patients was $54.7 \pm 16.6$ years (range, $1-78$ years).

The origin site of the tumor was the left atrium (LA) in 86 patients $(92.5 \%)$, right atrium in $4(4.3 \%)$, and left ventricle in $2(2.2 \%)$. Multiple myxomas in both atria and the right ventricle were present in one patient (1.1\%); his family history of myxoma was not identified. Among the tumors originating in the LA, the most common implant site was the fossa ovalis (76 patients, $81.7 \%$ ). A pedunculated mass was found in 63 patients $(67.6 \%)$, while the other 30 patients $(32.3 \%)$ had a sessile mass. Other cardiac surgeries were performed in 19 patients (20.4\%), with mitral valve surgery being the most common procedure (Table 1). Four patients underwent mitral valve surgery due to the organic change of the mitral valve (rheumatic mitral stenosis in 1 and degenerative mitral insufficiency 
Table 1 Cardiac surgeries performed concurrently with myxoma resection

\begin{tabular}{ll}
\hline Surgery & $\mathrm{n}(\%)$ \\
\hline Maze procedure & $4(4.3)$ \\
MVR & $3(3.2)$ \\
MVP & $2(2.2)$ \\
CABG & $2(2.2)$ \\
MVP + TVP & $1(1.1)$ \\
MVP + Maze procedure & $1(1.1)$ \\
MVR + Maze procedure & $1(1.1)$ \\
AVR + Maze procedure & $1(1.1)$ \\
PFO closure & $1(1.1)$ \\
RVOT release & $1(1.1)$ \\
VSD closure & $1(1.1)$ \\
Lung wedge resection & $1(1.1)$ \\
\hline AbbreVations: $A V R$ adtic VaVerepach
\end{tabular}

Abbreviations: $A V R$ aortic valve replacement, $C A B G$ coronary artery bypass grafting, MVP mitral valvuloplasty, MVR mitral valve replacement, PFO patent foramen ovale, RVOT right ventricular outflow tract, TVP tricuspid valvuloplasty, VSD ventricular septal defect

in 3). Four patients had myxoma-related mitral valve lesions. Four patients had mitral annular enlargement and one of them had a leaflet fibrotic change.

The most common symptom was dyspnea in $36 \mathrm{pa}-$ tients, 19 of whom had severe dyspnea greater than New York Heart Association functional classification III. Other cardiac or embolic symptoms included chest pain, palpitation, syncope, and stroke. Constitutional symptoms, such as fever, cough, weight loss, and headache, occurred in five patients, whereas 18 patients had an intracardiac mass detected incidentally without any symptoms (Table 2).

All myxomas were diagnosed by transthoracic echocardiography. However, if tumors other than myxomas were suspected, we performed transesophageal echocardiography, chest computed tomography, or magnetic resonance imaging.

Table 2 Preoperative clinical symptoms and signs

\begin{tabular}{ll}
\hline Symptom/sign & $\mathrm{n}(\%)$ \\
\hline Dyspnea & $36(38.7)$ \\
Chest pain & $20(21.5)$ \\
Palpitation & $8(8.6)$ \\
Stroke & $10(10.8)$ \\
Syncope & $5(5.4)$ \\
Fever & $1(1.1)$ \\
Cough & $1(1.1)$ \\
Headache & $1(1.1)$ \\
Weight loss & $1(1.1)$ \\
Nausea & $1(1.1)$ \\
Asymptomatic & $18(19.4)$ \\
\hline
\end{tabular}

Sixty-five patients underwent elective surgery, whereas 28 patients with severe symptoms or embolic risk underwent emergency surgery. Regarding elective surgery, preoperative coronary angiography was performed routinely in all male patients over 40 years of age and postmenopausal women. All surgeries were performed through median sternotomy. Routinely, the ascending aorta and both caval veins were cannulated, and a cardioplegic solution was infused in an antegrade or retrogade fashion. Retrograde cardioplegia infusion was used when aortic insufficiency was found on preoperative 2D echocardiography, or the operation time was expected to take longer due to combined operation like valve surgery. Surgery was performed via a biatrial approach in 69 patients (74.2\%), transseptal approach with right atriotomy and septotomy in $16(17.2 \%)$, and left atriotomy only in eight patients (8.6\%), depending on the size and location of the mass confirmed on preoperative 2D echocardiography.

Simple myxoma resection including the endocardium and attached stalk without any need to repair was performed in 17 patients, direct closure of the defect area was performed in 47, and patch closure with autopericardium or prosthetic material was performed in 29 . If the expected defect was too large to close directly, based on preoperative 2D echocardiography, autopericardium was harvested before pericardiotomy and fixed with glutaraldehyde for $5 \mathrm{~min}$. If the defect was recognized as too large to close directly, prosthetic material was used for closure; bovine pericardium (Supple Peri-Guard'; Synovis Surgical Innovations, St. Paul, MN) or a dacron patch (Bard ${ }^{\circ}$ Sauvage Filamentous Knitted Polyester Fabric; Bard Peripheral Vascular Inc., AZ) was used according to the preference of the surgeon. Mean cardiopulmonary bypass time was $80.7 \pm$ 39.0 min (range, 19-231 min), and mean aortic crossclamping time was $51.3 \pm 27.5 \mathrm{~min}$ (range, 9-153 min).

Mean myxoma size based on the longest length was $4.73 \pm 1.92 \mathrm{~cm}$ (range, $1.2-11.0 \mathrm{~cm}$ ), and a giant myxoma over $10 \mathrm{~cm}$ in length was found in two patients $(10.0 \times$ $4.0 \times 2.0 \mathrm{~cm}$ and $11.0 \times 10.0 \times 3.5 \mathrm{~cm}$ ) (Fig. 1). One patient was recommended surgical resection of a mass located on the fossa ovalis measuring approximately $1.66 \times 1.6 \times$ $1.0 \mathrm{~cm}$. However, she refused the surgery and revisited 15 months later with severe dyspnea resulting from functional mitral stenosis. Preoperative 2D echocardiography revealed that the mass had grown to $7.7 \times 3.38 \times 1.0 \mathrm{~cm}$ (Fig. 2). Surgical resection was performed successfully.

Long-term survival was assessed based on the National Health Insurance database. Results are presented as mean \pm SD. Long-term cumulative survival was analyzed using the Kaplan-Meier method. Analyses were performed using PASW version 18.0 (IBM Corporation, Armonk, NY, USA). This study was approved by the Institutional Review Board of Chonnam National University Hospital (IRB No. CNUH-2016-217), which 


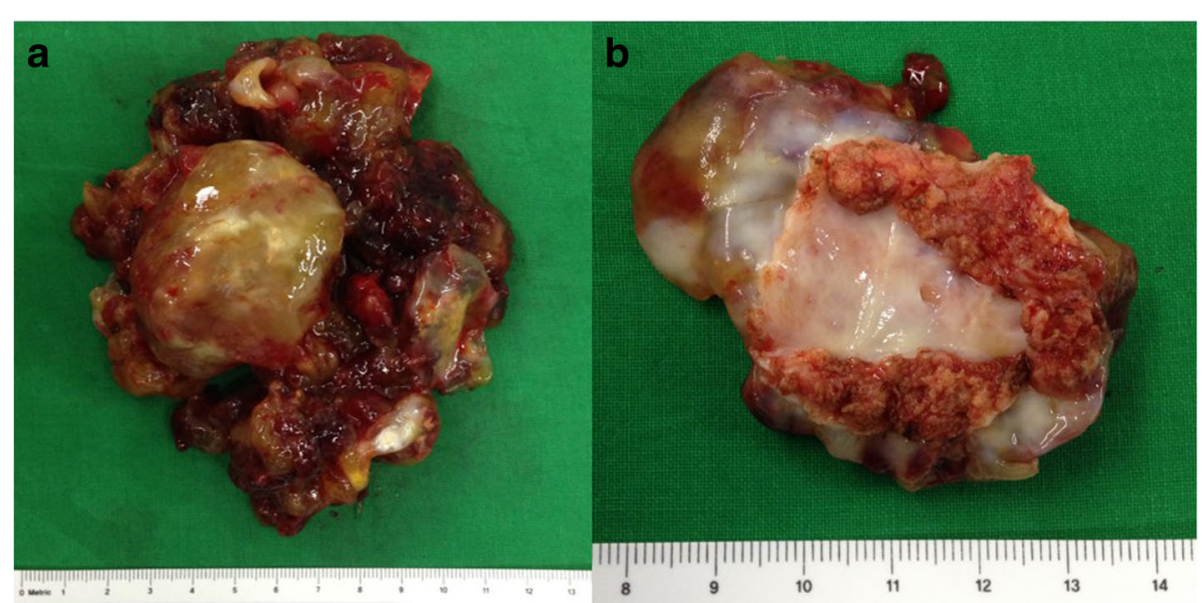

Fig. 1 Images of a giant myxoma. a The resected myxoma is huge. $\mathbf{b}$ The resected myxoma has a broad base of approximately $4 \mathrm{~cm}$ in diameter

waived the requirement for informed patient consent because of the retrospective nature of the study.

\section{Results}

The most common postoperative complications were atrial fibrillation in four patients and wound infection in
3. Newly developed atrial fibrillation occurred after a biatrial or transseptal approach in two patients each ( $p$ $=0.136$ ), with no conduction disturbance postoperatively. Other complications included low cardiac output syndrome, complete atrioventricular block, cerebral hemorrhage, hoarseness, pneumonia, and acute cholangitis.

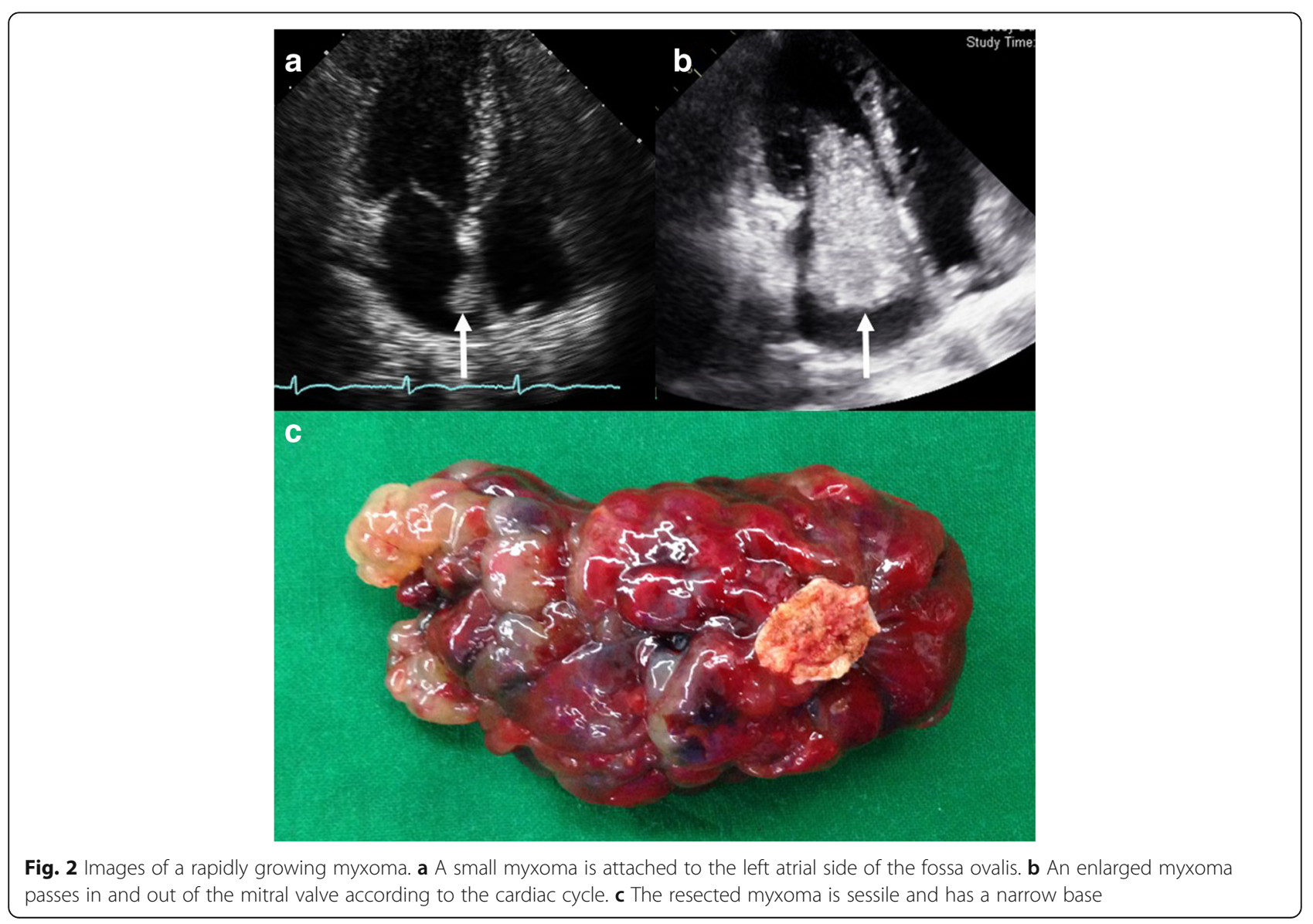


In-hospital mortality occurred in three patients (3.2\%) due to postoperative pneumonia, low cardiac output syndrome (the patient had a ventricular septal defect with a myxoma in the left ventricle), or metabolic acidosis and dilutional coagulopathy after massive transfusion caused by intraoperative coronary sinus rupture.

Mean follow-up duration was $9.9 \pm 7.8$ years (range, 0-29 years), and 12 of 93 patients became ineligible for the National Health Insurance; these 12 patients were regarded as dead because change in nationality was not identified during this period. The 5-, 10-, and 30-year survival rates were $92.9,87.2$ and $75.5 \%$, respectively (Fig. 3). Myxoma recurred in two patients (2.1\%) during the follow-up period. One patient with multiple myxomas in the LA, right atrium, and right ventricle underwent a reoperation 79 months after the primary operation. The recurred masses were located on the LA roof, right atrial septum, and trabecula of the right ventricle. All masses were widely resected, the septal defect was reconstructed using a Dacron patch, and plication was performed for LA roof repair. The other patient experienced cerebral infarction 20 months after the primary surgery, and 2D echocardiography revealed a mass on the previously resected margin; myxoma could not be ruled out completely. The patient refused a reoperation, and the mass did not grow during the follow-up period. These recurred patients underwent direct closure of the defect after tumor removal. No recurred tumor was evident in patients with simple myxoma resection or patch closure of the defect. However, this was not statistically significant because there were few recurred cases.

\section{Discussion}

Myxoma is the most common primary cardiac tumor, which frequently occurs in middle age and is more common in women than in men [2-5]. In our data, the mean age of the patients was 54.7 years at the time of surgery, and $86 \%$ were aged over 40 years. In addition, myxoma was 2 times more common in women than in men.

Myxomas vary in size, but the growth rate is difficult to document because they are usually removed after diagnosis [6-9]. However, in our study, the one patient who underwent surgery 15 months after initial diagnosis showed a rapid growth rate of $0.41 \mathrm{~cm} /$ month.

Although operative mortality is reported to be within $5 \%$, the rate is increased with myxoma occurring in the ventricle $[3,5,10,11]$. In our data, in-hospital mortality occurred in three patients. One patient died from low cardiac output syndrome after extensive resection of the left ventricle, while the other two patients died from pneumonia or coronary sinus rupture, which may occur after cardiac surgery. Pneumonia after cardiac surgery is

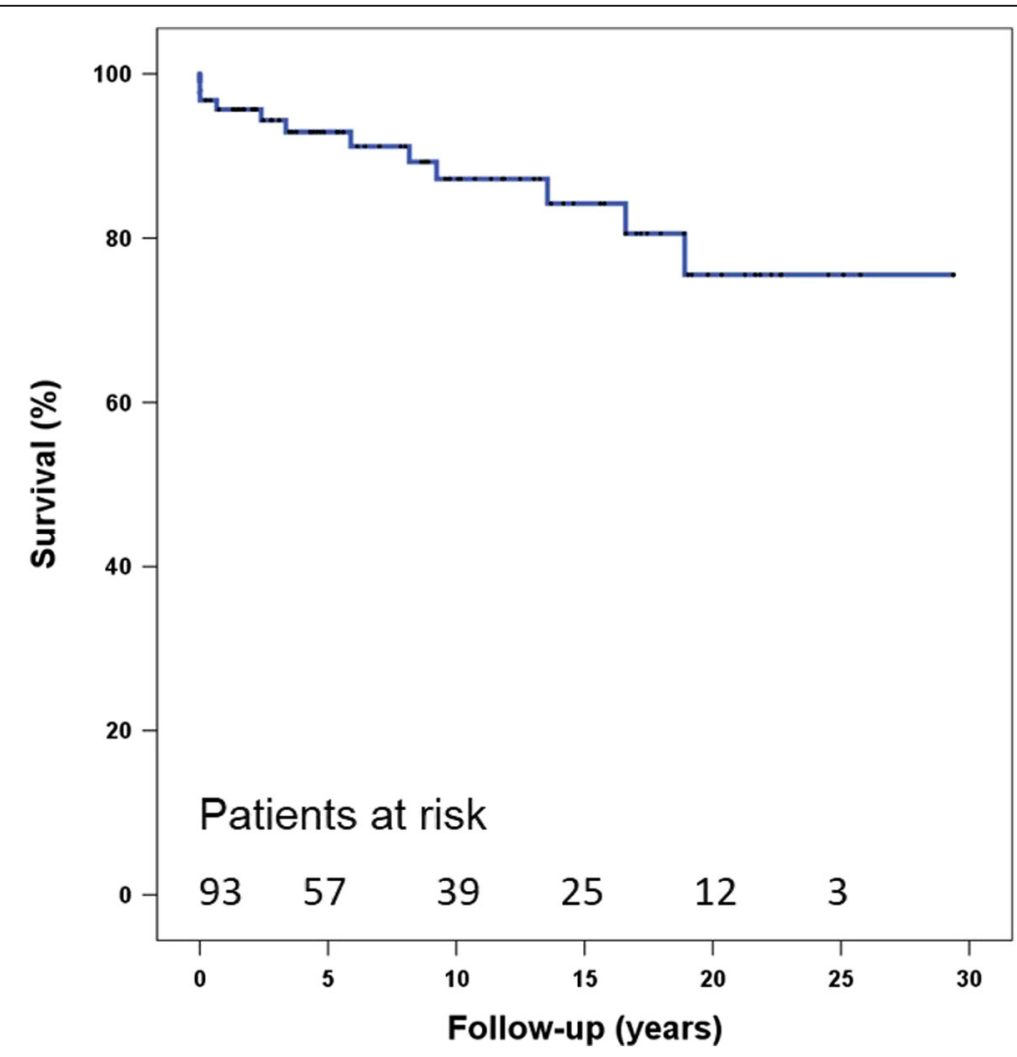

Fig. 3 Long-term cumulative survival after myxoma resection 
one of the most common causes of postoperative mortality, and coronary sinus rupture during retrograde cardioplegia infusion is also a possible complication during cardiac surgery. These complications may occur due to the nature of cardiac surgery rather than myxoma itself. Although myxoma resection is relatively simple compared with other cardiac surgeries, it does require cardiopulmonary bypass during cardiac arrest. Therefore, postoperative complications may occur as in other more complex cardiac surgeries, and should be recognized.

Regarding the surgical approach, a biatrial approach is helpful to determine the correct resection margin by confirming the tumor pedicle under direct visualization, to minimize manipulation of the tumor, to find hidden myxomas by inspection of all heart chambers, and to secure the septal defect after resection of a tumor located on the atrial septum [12]. On the other hand, a transseptal approach through right atriotomy may provide adequate mass exposure and, as a result, low recurrence and easy repair of a single incision on the right atrium [13]. However, if the myxoma is sessile, has a broad base, and is attached to the atrial septum, a biatrial approach, rather than a transseptal approach, may reduce the risk of injury and tumor emboli. Even though a transseptal approach is simpler than a biatrial approach, it is only useful when the myxoma is pedunculated and has a narrow stalk. We primarily used biatrial incisions, but, a transseptal approach or left atriotomy only was used for resection of small myxomas confirmed on preoperative 2D echocardiography. Our institution does not have a guideline regarding the incision site as it relates to tumor size. However, if the largest tumor is less than 2 $\sim 3 \mathrm{~cm}$ in size, wherein the tumor fully can be removed through a transseptal incision without breaking, the base of the stalk is narrow, and the motion of the tumor is active according to the heart beat on 2D echocardiography, we use a transseptal approach. In all other cases, a left atriotomy should be performed first. The position and shape of the tumor is evaluated, and, if the tumor can be removed without manipulation, it is removed without an additional incision. If the stalk is short or of a sessile form, we perform an additional right atriotomy to secure the resection margin. Because all tumors can be detected on preoperative transthoracic echocardiography due to advances in imaging techniques, and additional intracardiac evaluation is performed during surgery using transesophageal echocardiography, especially when left atriotomy only is performed, additional cardiac incisions for evaluation of all cardiac chambers may not be necessary.

The recurrence rate after myxoma resection has been reported to be less than $5 \%[3-5,12]$. In our data, two patients (2.1\%) had recurrence. One patient had multiple myxomas and underwent a reoperation. The other patient was suspected to have recurrence on the atrial septum, but it was not confirmed histologically. Because we could not rule out myxoma completely, we regarded it as recurrence on the previously resected margin. Myxoma recurrence is caused by incomplete resection or tumor seeding during mass manipulation [14]. Our two cases of recurrence were thought to be caused by incomplete primary resection because they were located on the resection margin. Therefore, some authors insist on wide resection to prevent recurrence following incomplete resection [15]. However, other reports claim that simple tumor resection is sufficient because of the low recurrence rate $[4,16]$. Our recurred patients underwent full-layer resection including the stalk and primary closure, and no patient who underwent only simple myxoma resection without defect repair was recurred. Therefore, it is thought that all myxoma patients are not necessary taken full-layer resection. However, in cases of myxoma occurring at a relatively young age, with ventricular origin, family history, Carney complex, or multiple myxomas, full-layer wide resection is recommended because of the increased recurrence rate $[3,5,12,17]$.

Our study has several limitations. First, this was a retrospective study. However, this study design was inevitable because cardiac tumors are extremely rare and early surgical resection is the treatment of choice. Second, we estimated mortality as total death without considering cardiac or sudden death separately. Although this does not reflect disease-related mortality specifically, it is thought that total death lowers selection bias.

\section{Conclusions}

Clinical outcomes of myxoma resection are acceptable, but complications associated with cardiopulmonary bypass or cardiac arrest should be recognized. Although recurrence is low and is not affected by surgical method, wide resection is generally recommended in patients with increased likelihood of recurrence.

\section{Abbreviations \\ 2D: 2 dimentional; LA: Left atrium \\ Acknowledgements \\ Not applicable. \\ Funding \\ This work was not funded.}

Availability of data and materials

Data available on request from the authors.

Authors' contributions

KS was a major contributor in writing the manuscript. GS carried out the statistical analysis. Y and IS participated in the data collection. $\mathrm{KJ}, \mathrm{BS}$ and $\mathrm{BH}$ participated in the design of the study. BH and SG conceived of the study and participated in its design and coordination. SG and BH contributed equally to this article. All authors read and approved the final manuscript. 


\section{Competing interests}

The authors declare that they have no competing interests.

\section{Consent for publication}

Not applicable.

Ethics approval and consent to participate

This study was approved by the Institutional Review Board of Chonnam

National University Hospital (IRB No. CNUH-2016-217).

\section{Publisher's Note}

Springer Nature remains neutral with regard to jurisdictional claims in published maps and institutional affiliations.

Received: 27 October 2016 Accepted: 21 March 2017

Published online: 27 March 2017

\section{References}

1. Prichard RW. Tumors of the heart; review of the subject and report of 150 cases. AMA Arch Pathol. 1951;51:98-128.

2. Burke A, Tavora F. The 2015 WHO classification of tumors of the heart and pericardium. J Thorac Oncol. 2016;11:441-52.

3. Bjessmo S, Ivert T. Cardiac myxoma: 40 years' experience in 63 patients. Ann Thorac Surg. 1997;63:697-700.

4. Centofanti P, Di Rosa E, Deorsola L, Dato GM, Patane F, La Torre M, et al. Primary cardiac tumors: early and late results of surgical treatment in 91 patients. Ann Thorac Surg. 1999;68:1236-41.

5. Garatti A, Nano G, Canziani A, Gagliardotto P, Mossuto E, Frigiola A, et al. Surgical excision of cardiac myxomas: twenty years experience at a single institution. Ann Thorac Surg. 2012;93:825-31.

6. Walpot J, Shivalkar B, Rodrigus I, Pasteuning WH, Hokken R. Atrial myxomas grow faster than we think. Echocardiography. 2010;27:E128-31.

7. Malekzadeh S, Roberts WC. Growth rate of left atrial myxoma. Am J Cardiol. 1989;64:1075-6.

8. Rey MJ, Tamm C, Faidutti B, Luthy P, Unger PF. Growth rate of primary left atrial myxoma. Eur Heart J. 1993;14:1146-7.

9. Ullah W, McGovern R. Natural history of an atrial myxoma. Age Ageing. 2005;34:186-8

10. ElBardissi AW, Dearani JA, Daly RC, Mullany CJ, Orszulak TA, Puga FJ, et al. Analysis of benign ventricular tumors: long-term outcome after resection. J Thorac Cardiovasc Surg. 2008;135:1061-8.

11. Meller J, Teichholz LE, Pichard AD, Matta R, Litwak R, Herman MV, et al. Left ventricular myxoma: echocardiographic diagnosis and review of the literature. Am J Med. 1977:63:816-23.

12. Jones DR, Warden HE, Murray GF, Hill RC, Graeber GM, Cruzzavala JL, et al. Biatrial approach to cardiac myxomas: a 30-year clinical experience. Ann Thorac Surg. 1995;59:851-5. discussion 5-6.

13. Sellke FW, Lemmer Jr JH, Vandenberg BF, Ehrenhaft JL. Surgical treatment of cardiac myxomas: long-term results. Ann Thorac Surg. 1990;50:557-61.

14. Shinfeld A, Katsumata T, Westaby S. Recurrent cardiac myxoma: seeding or multifocal disease? Ann Thorac Surg. 1998;66:285-8.

15. Gerbode F, Kerth WJ, Hill JD. Surgical management of tumors of the heart. Surgery. 1967;61:94-101.

16. Attar S, Lee YC, Singleton R, Scherlis L, David R, McLaughlin JS. Cardiac myxoma. Ann Thorac Surg. 1980;29:397-405.

17. Shah IK, Dearani JA, Daly RC, Suri RM, Park SJ, Joyce LD, et al. Cardiac myxomas: a 50-year experience with resection and analysis of risk factors for recurrence. Ann Thorac Surg. 2015;100:495-500.

\section{Submit your next manuscript to BioMed Central and we will help you at every step:}

- We accept pre-submission inquiries

- Our selector tool helps you to find the most relevant journal

- We provide round the clock customer support

- Convenient online submission

- Thorough peer review

- Inclusion in PubMed and all major indexing services

- Maximum visibility for your research

Submit your manuscript at www.biomedcentral.com/submit
Biomed Central 